\title{
Hydrometallurgical recycling of lithium-ion batteries by reductive leaching with sodium metabisulphite
} \author{
Fernanda Margarido ${ }^{a}$ \\ ${ }^{a}$ Center for Innovation, Technology and Policy Research - IN+, Instituto Superior Técnico, University of Lisbon, $1049-001$ Lisboa, Portugal \\ ${ }^{\mathrm{b}}$ LNEG - Laboratório Nacional de Energia e Geologia, I.P., Campus do Lumiar, 1649-038 Lisboa, Portugal \\ ${ }^{\text {c } C E R E N A ~-~ C e n t r o ~ d e ~ R e c u r s o s ~ N a t u r a i s ~ e ~ A m b i e n t e, ~ I n s t i t u t o ~ S u p e r i o r ~ T e ́ c n i c o, ~ U n i v e r s i t y ~ o f ~ L i s b o n, ~ 1049-001 ~ L i s b o a, ~ P o r t u g a l ~}$
}

Nathália Vieceli ${ }^{\mathrm{a}, *}$, Carlos A. Nogueira ${ }^{\mathrm{b}}$, Carlos Guimarães ${ }^{\mathrm{c}}$, Manuel F.C. Pereira ${ }^{\mathrm{c}}$, Fernando O. Durão ${ }^{\mathrm{c}}$,

\section{A R T I C L E I N F O}

\section{Article history:}

Received 19 July 2017

Revised 15 September 2017

Accepted 27 September 2017

Available online 10 October 2017

\section{Keywords:}

Spent lithium-ion batteries

Recycling

Sodium metabisulphite

Reductive leaching

\begin{abstract}
A B S T R A C T
The hydrometallurgical extraction of metals from spent lithium-ion batteries (LIBs) was investigated. LIBs were first dismantled and a fraction rich in the active material was obtained by physical separation, containing $95 \%$ of the initial electrode, $2 \%$ of the initial steel and $22 \%$ of plastic materials. Several reducers were tested to improve metals dissolution in the leaching step using sulphuric acid. Sodium metabisulphite led to the best results and was studied in more detail. The best concentration of $\mathrm{Na}_{2} \mathrm{~S}_{2} \mathrm{O}_{5}$ was $0.1 \mathrm{M}$. The metals dissolution increased with acid concentration, however, concentrations higher than $1.25 \mathrm{M}$ are unnecessary. Best results were reached using a stirring speed of $400 \mathrm{~min}^{-1}$. The metals leaching efficiency from the active material ( $\mathrm{Li}, \mathrm{Mn}, \mathrm{Ni}, \mathrm{Co}$ ) increased with the temperature and was above $80 \%$ for temperatures higher than $60^{\circ} \mathrm{C}$. The dissolution of metals also rose with the increase in the liquid/solid ratio $(\mathrm{L} / \mathrm{S})$, however, extractions above $85 \%$ can be reached at $\mathrm{L} / \mathrm{S}$ as lower as $4.5 \mathrm{~L} / \mathrm{kg}$, which is favourable for further purification and recovery operations. About $90 \%$ of metals extraction can be achieved after only $0.5 \mathrm{~h}$ of leaching. Sodium metabisulphite can be an alternative reducer to increase the leaching of Li, Mn, Co, and Ni from spent LIBs.
\end{abstract}

(c) 2017 Elsevier Ltd. All rights reserved.

\section{Introduction}

Lithium-ion batteries (LIBs) have advantages over other rechargeable batteries, which have made them widely used in portable electronic devices, such as personal computers, video cameras and mobile phones since they were first commercialized in 1991. For that, contribute excellent properties such as high energy and power densities, high battery voltage, long chargingdischarging cycles, long lifespan and large operating temperature range (Zhang et al., 1998).

Given concerns about the carbon dioxide footprint, the interest in alternative energy sources has increased and represents a great market for lithium-based batteries, highlighting the electric mobility (electric (EV), plug-in (PHEV) and hybrid (HEV) vehicles) and electrochemical energy storage for renewable energy conversion (solar and wind-powered electric generation) (Goonan, 2012). Electric vehicles are crucial for the sustainable transport systems future and their wide global deployment is necessary to meet

\footnotetext{
* Corresponding author.

E-mail address: nathalia.vieceli@tecnico.ulisboa.pt (N. Vieceli).
}

sustainability targets. The EV stock reached 1.26 million in 2015 , 100 times more than in 2010 and new registrations of EVs increased by 70\% between 2014 and 2015, with over 550,000 vehicles being sold worldwide in 2015 (OECD/IEA, 2016).

Lithium is classified by the American Physical Society (APS) and Materials Research Society (MRS) as an "energy-critical element", given its role in emerging sustainable energy sources and the fact that it might encounter supply risks and a shortage could significantly affect the adoption of some energy technologies (Hurd et al., 2012). Several countries worldwide are establishing national alternative energy policies that have the potential to considerably increase lithium demand. Moreover, energy storage systems could be beneficiaries of the widespread research and development of LIBs for the transportation sector, which can help make it more affordable (Jaskula, 2014; Diouf and Pode, 2015). Consumer and industrial electronics accounted for about $78 \%$ of the global lithium-ion battery market revenues, while transportation applications such as EVs, HEVs and PHEVs accounted for approximately $20 \%$, and grid applications represented about $2 \%$. Moreover, global lithium-ion battery consumption increased by an average of $27 \%$ per year from 2011 to 2014 (Jaskula, 2014; Moss et al., 2011). 